\title{
SISTEM MANAJEMEN LEMBAGA PENELITIAN DAN PENGABDIAN KEPADA MASYARAKAT BERBASIS WEB
}

\author{
Ahmad Saprun Haris ${ }^{1}$, Sofiansyah Fadli ${ }^{2}$,Ahmad Tantoni ${ }^{3}$ \\ 1,2,3Program Studi Teknik Informatika \\ Sekolah Tinggi Manajemen Informatika dan Komputer (STMIK) Lombok, \\ Jln. Basuki Rahmat No. 105 Praya, Lombok Tengah, Faks. 0370653109 \\ 1ahmadsaprunharies@gmail.com, ${ }^{2}$ sofiansyah182@gmail.com, ${ }^{3}$ ahmad.tantoni@students.amikom.ac.id.
}

\begin{abstract}
The need of information in the current technology cal era is very necessary. The technology of information can be applied in all areas, which is useful for saving time, costs and energy needed. One of them is in area of education, College of Information and Camputer Management Lombok Praaya (STMIK), utilizes information technology in its application, especially at the institute for Research and community Service of STMIK Lombok Praya. This Management Information System and Community Service institute in STMIK Lombok Praya which is using the waterfall method and was built by using framework codeiter,MySQL,for Database storage and by using Twitter bootstrap to improve the appearance of a website page.

The results of this study can be useful to facilitate the management and to organize the research data and service that were done by both STMIK Lombok Praya lecturers and srudents.
\end{abstract}

Keywords: Information System, Waterfal Method, Framework, Codeigniter, MySQL and Twitter Boostrap

Abstrak

Kebutuhan informasi pada zaman teknologi sekarang ini sangat diperlukan. Teknologi informasi dapat diterapkan dalam semua bidang, yang berguna untuk menghemat waktu, biaya dan tenaga yang dibutuhkan. Salah satunya pada bidang pendidikan, Sekolah Tinggi Manajemen Informatika dan Komputer (STMIK) Lombok Praya, memanfaatkan teknologi informasi dalam penerapannya khususnya pada Lembaga Penelitian dan Pengabdian kepada Masyarakat STMIK Lombok Praya.

Sistem Informasi Manajemen Lembaga Penelitian Dan Pengabdian Kepada Masyarakat STMIK Lombok Praya Berbasis Web ini dirancang dengan menggunakan metode Waterfall dan dibangun dengan menggunakan framework codeigniter, MySQL untuk penyimpanan databasenya dan menggunakan twitter bootstrap untuk memperbagus tampilan sebuah halaman website.

Hasil penelitian ini dapat bermanfaat untuk mempermudah pengelolaan dan mengorganisir data-data hasil penelitian dan pengabdian yang dilakukan baik oleh dosen maupun mahasiswa STMIK Lombok Praya.

Kata Kunci : Sistem Informasi, Metode Waterfall ,Framework, Codeigniter, MySQL danTwitter Boostrap

\section{Pendahuluan}

Sekarang ini sebagian besar kegiatan telah menggunakan jasa komputer yang digunakan sebagai alat bantu dalam penyelesaian masalah pekerjaan. Jika dilihat dari segi kegunaannya, komputer dapat memberikan informasi dengan cepat, tepat, efisien dan dapat mengurangi kesalahan yang mungkin saja terjadi. Selain itu, komputer dapat pula memberikan informasi yang dapat dipakai untuk mengambil suatu keputusan. Pada bidang pendidikan, khususnya
Sekolah Tinggi Manajemen Informatika dan Komputer Lombok Praya sebagai salah perguruan tinggi yang baru berdiri dalam beberapa tahun, mencoba untuk membuat sistem yang digunakan untuk mempermudah suatu pekerjaan. Salah satunya dalam Lembaga Penelitian dan Pengabdian kepada Masyarakat (LPPM) STMIK Lombok Praya.

LPPM merupakan lembaga atau sebuah unit kegiatan yang berfungsi mengelola semua data kegiatan seperti data penelitian, data pengabdian dan data berupa informasi yang 
berkaitan dengan LPPM itu sendiri. Saat ini datadata penelitian, pengabdian masih dikelola secara manual dengan menggunakan aplikasi microsoft office, sehingga pencatatan data dilakukan pada banyak file yang berbeda yang dapat disimpan pada tempat yang berbeda. Hal ini mengakibatkan membutuhkan waktu yang tidak sebentar pada saat melakukan manipulasi terhadap data untuk menyusun laporan dan juga mengakibatkan integritas dan keamanan data yang tidak terjamin.

Ketiadaan sistem pengelolaan data dan penyimpanan data khususnya pada LPPM menjadi masalah yang sering kali ditemukan seperti manajemen data yang kurang tersusun dan tersimpan secara rapi. Selain itu juga saat ini belum adanya media khusus yang dapat membantu secara khusus kepala LPPM dan stap dalam menunjang kinerja serta kegiatan sehariharinya, yang antara lain seperti publikasi penelitian, serta informasi mengenai kegiatan yang diselenggarakan baik oleh internal maupun eksternal yang diselenggarakan oleh Kopertis, Dikti, pihak swasta seperti Bank dan stakeholders lainnya. Sedangkan untuk data kegiatan pengabdian pada masyarakat sendiri seperti pelatihan komputer gratis bagi siswasiswi maupun guru-guru SMA sederajat dan juga masyarakat umum yang belum mengenal komputer. Sistem pengelolaan data pada LPPM diharapkan mampu menjadi solusi dalam menyelesaikan masalah-masalah yang ada pada saat ini.

Dengan berbagai pertimbangan tersebut maka diperlukan suatu sistem yang mampu mengelola data dan menyimpan data. Sistem yang dimaksud adalah Sistem Manajemen Lembaga Penelitian Dan Pengabdian Kepada Masyarakat Berbasis Web. Sistem ini dipilih karena memiliki fleksibilitas yang lebih baik dibandingkan sistem yang lain, terutama dilihat dari kemampuan untuk diakses oleh para pengguna secara bersamaan tanpa tergantung oleh tempat dan waktu pengaksesan. Dengan adanya sistem tersebut diharapkan unsur perencanaan bisa dilaksanakan dengan sebaikbaiknya dilingkungan STMIK Lombok Praya khususnya LPPM.

\section{Tinjauan Pustaka}

Penelitian sebelumnya yang berkaitan dengan perancangan dan pembangunan sistem informasi manajemen lembaga penelitian dan pengabdian pada masyarakat telah banyak dilakukan adalah sebagai berikut:

Muhammad

Hamkadkktahun (2014),dalampenelitian yang bertema Sistem
Pendukung Keputusan dosen berprestasi berdasarkan kenerja penelitian dan pengabdian masyrakat metode yang di gunakana dalah metode TOPSIS di mana Metode inidapat menyelesaikan permasalah pengambilan keputusan pada kondisi yang tidak tersruktur dan bersipat multikriteria. Hasil yang didapatkan dari penelitiannya adalah SPK dapat membantu pengambilan keputusan dalam memberikan rekomendasi keputusan dosen berpretasi yang tepat dan lebihobyetif.

Harmi Riyadi, dkk tahun (2014), dengan judul "Rancang Bangun Sistem Informasi Pengabdian dan Penelitian Dosen U'Budiyah Indonesia (Studi kasus : Universitas U'Budiyah Indonesia Banda Aceh)". Dalam penelitian ini dibangun aplikasi berbasis web yang dapat menyajikan informasi yang meliputi penginputan data penelitian dan data penelitian, input data pengabdian dan data pengabdian dan input data dosen dan data dosen. Penyajian dalam bentuk basis data yang update oleh administrator, sehingga informasi yang diperoleh lebih cepat, mudah, efektif, efisien, aman dan akurat.

Ahmad Kurniawatidkk tahun (2015), dalmam penelitian yang bertema Penerapan Dashboaed business intelligence pada penelitian pelayanan pengabdian kepada masyarakat dan kerjasama. Metode yang digunakana dalah metode Business Intelligence Roadmap. Hasil yang didapatkan dalam penelitiannya adalah memberikan informasi yang akurat kepada ketua timborong tantang data penelitian dan pengapdian dosen selam 5 tahun terakhir.

Nurmi dkktahun (2015), dalam penelitiannya yang bertema Membangun Sistem Pendukung Keputusan penelitian dosen berbasis Online pada unit penelitian,Pengembangan dan pengabdiankepala Masyarakat (UP3M) STKIP PGRI Sumatera Barat. Hasil yang di dapatkan dapat membantu mengatasi masalah manajemen UP3M sehingga menghasilkan keputusan yang terstruktur dengan memenuhi standar Dikti dengan keputusan yang lebihcepat, danakurat

Jery Ariska tahun (2016), pada penelitiaannya yang berjudul Rancang bangun sistem informasi manajemen asset sekolah menggunakan teknik Labelling QR code pada MAN 2 MODEL Pekanbaru .Hasil dari penelitiannya inimenggunakan metode pengembangan sistem Watarffal dan menggunakan teknik Labelling QR Code.

\section{Waterfall}

Menurut Presman, (2012), Metede Waterfall sering disebut dengan air terjun, juga 
sering dinamakan dengan siklus hidup klasik (classic life cycle), dimana hal ini menggambarkan pendekatan yang sistematis dan juga berurutan pada pengembangan perangkat lunak, dimulai dengan spesifikasi kebutuhan pengguna lalu berlanjut melalui tahapan-tahapan perencanaan (planning), pemodelan (modeling), konstruksi (construction), serta penyerahan sistem ke para pelanggan/pengguna (deployment), yang diakhiri dengan dukungan pada perangkat lunak lengkap yang dihasilakan. Tahapan metode waterfall dapat dilihat pada gambar dibawah ini.

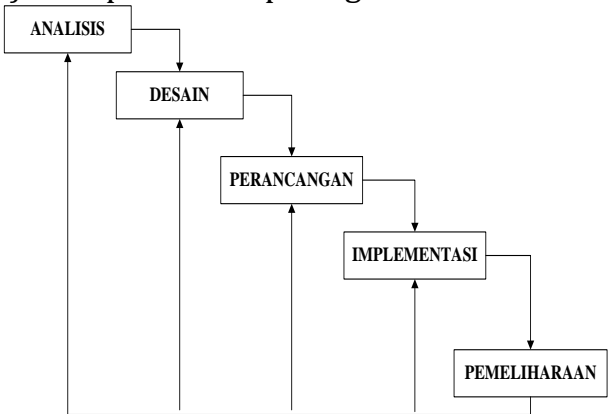

Gambar 2.1 Model Waterfall

Keterangan dari gambar 1.1 antara lain:

1. Analisis kebutuhan perangkat lunak

Proses pengumpulan kebutuhan dilakukan secara intensif untuk menspesifikasikan kebutuhan perangkat lunak agar dapat dipahami seperti apa yang dibutuhkan user. Spesifikasi kebutuhan perangkat lunak

2. Desain

Desain perangkat lunak adalah proses multi langkah yang focus pada desain pembuatan program perangkat lunak termasuk struktur data, arsitektur perangkat lunak, representasi antar muka dan prosedur pengkodean.

3. Perancangan

Desain harus ditranslasikan kedalam program perangkat lunak. Hasil dari tahap ini adalah program komputer sesuai dengan desain yang telah dibuat pada tahap desain

4. Inplementasi

Inplementasi focus pada perangkat lunak dari segi logik dan fungsional serta memastikan bahwa semua bagian sudah diuji. Hal ini dilakukan untuk meminimalisir kesalahan (error) dan memastikan keluaran yang dihasilkan sesuai dengan yang diinginkan

5. Pemeliharaan

Tidak menutup kemungkinan sebuah perangkat lunak mengalami perubahan ketika sudah dikirim ke user. Perubahan bisa terjadi adanya kesalahan yang muncul dan tidak terdeteksi saat pengujian atau perangkat lunak harus beradaptasi dengan lingkungan baru. Tahap pendukung atau pemeliharaan dapat mengulangi proses pengembangan mulai dari analisis spesifikasi untuk perubahan perangkat lunak yang sudah ada, tapi tidak untuk membuat perangkat lunak barus Adapun keuntungan dan kelemahan sistem pengembanagan Waterffall sebagaiberikut:

Tabel2.1Keuntungandan Kelemahan Waterffall

\begin{tabular}{|l|c|}
\hline Keuntungan & Kelemahan \\
\hline 1. Kualitas dari sistem yang & 1. Pengembangan tidak dapat \\
dihasilkan akan baik. & dilakukan secara berulang sebehmm \\
2. Document Pengembangan avstem & teria dinya suatu produk \\
sangat terorganisasi.kama setiap. & 2. Kesalahan kecil akan berakibat \\
fase harus terselsaikan dengan & pada tahapan selanjutnva \\
lengkan sebelum fase berikutnya & \\
& \\
& \\
\hline
\end{tabular}

1. MetodeAnalisa(SWOT)

Menurut Rangkuti (2009) Analisis SWOT adalah proses identifikasi berbagai faktor secara sistematis guna menentukan rumusan yang tepat dan melakukan strategi perusahaan yang terbaik. Analisis ini berdasarkan pada logika yang dapat memaksimalkan kekuatan (Strengths) dan peluang (Opportunities), namun secara bersamaan dapat meminimalkan kelemahan(Weaknesses) dan ancaman (Threats). Proses pengambilan keputusan strategis perusahaan selalu berkaitan erat dengan pengembangan misi, visi, tujuan, strategi serta kebijakan perusahaan. Oleh karenanya perencanaan yang strategis sangat memerlukan analisa-analisa dari masing masing SWOT ini (kekuatan, kelemahan, peluang, dan ancaman) di lingkungan perusahaan saat ini. Menurut David,Fred R. (2005) Berikut Penjelasan lengkap mengenai SWOT akan kita rinci satu persatu.

1. Strengths (Kekuatan)

Strengths adalah segala sumber daya yang dimiliki perusahaan baik sumber daya manusia, keterampilan, soft skill, maupun ke unggulan lain yang dimiliki perusahaan yang mana dihubungkan dengan para pesaing perusahaan serta kebutuhan pasar.

2. Weakness (Kelemahan)

Weakness merupakan suatu keterbatasan serta kekurangan dalam sebuah perusahaan.

3. Opportunities (Peluang)

Opportunities merupakan suatu kesempatan yang sangat penting yang sangat dituggu oleh masing-masing perusahaan. 


\section{Threats (Ancaman)}

Threats adalah situasi penting yang tidak menguntungkan perusahaan.

2. Metode Testing (Black Box)

Pengujian menggunakan sekumpulan aktifitas validasi, dengan pendekatan black box testing. Menurut Shalahuddin dan Rosa (2011), black box testing adalahmenguji perangkat lunak dari segi spesifikasi fungsional tanpa menguji desain dankode program. Pengujian dimaksudkan untuk mengetahui apakah fungsifungsi, masukan, dan keluaran dari perangkat lunak sesuai dengan spesifikasi yang dibutuhkan. Pengujian kotak hitam dilakukan dengan membuat kasus uji yang bersifat mencoba semua fungsi dengan memakai perangkat lunak apakah sesuaidengan spesifikasi yang dibutuhkan. Kasus uji yang dibuat untuk melakukan pengujian black box testing harus dibuat dengan kasus benar dan kasus salah.

Menurut Pressman (2010), black box testing juga disebut pengujian tingkah laku, memusat pada kebutuhan fungsional perangkat lunak. Teknik pengujian black box memungkinkan memperoleh serangkaian kondisi masukan yang sepenuhnya menggunakan semua persyaratan fungsional untuk suatu program. Beberapa jenis kesalahan yang dapat diidentifikasi adalah fungsi tidak benar atau hilang, kesalahan antar muka, kesalahan pada struktur data (pengaksesan basis data), kesalahan performasi, kesalahan inisialisasi dan akhir program.

Black Box Testing cenderung untuk menemukan hal-hal berikut:

1. Fungsi yang tidak benar atau tidak ada.

2. Kesalahan antarmuka (interface errors).

3. Kesalahan pada struktur data dan akses basis data.

4. Kesalahan performansi (performance errors).

5. Kesalahan inisialisasi dan terminasi

6. Pengujian didesain untuk menjawab pertanyaan-pertanyaan berikut:

a. Bagaimana fungsi-fungsi diuji agar dapat dinyatakan valid?

b. Input seperti apa yang dapat menjadi bahan kasus uji yang baik?

c. Apakah sistem sensitif pada input-input tertentu?

d. Bagaimana sekumpulan data dapat diisolasi?

e. Berapa banyak rata-rata data dan jumlah data yang dapat ditangani sistem?

f. Efek apa yang dapat membuat kombinasi data ditangani spesifik pada operasi sistem?

\section{Hasil Dan Pembahasan}

a. Sistem Yang Diusulkan

Adapung sistem yang diusulkan penulis, dimana sistem ini mengubah sistem yang lama menjadi sistem yang diusulkan, sehingga di dalamnya terdapat beberapa penambahan dan pengurangan pada bagian proses.

Berikut ini adalah penjelasan sistem yang diusulkan:

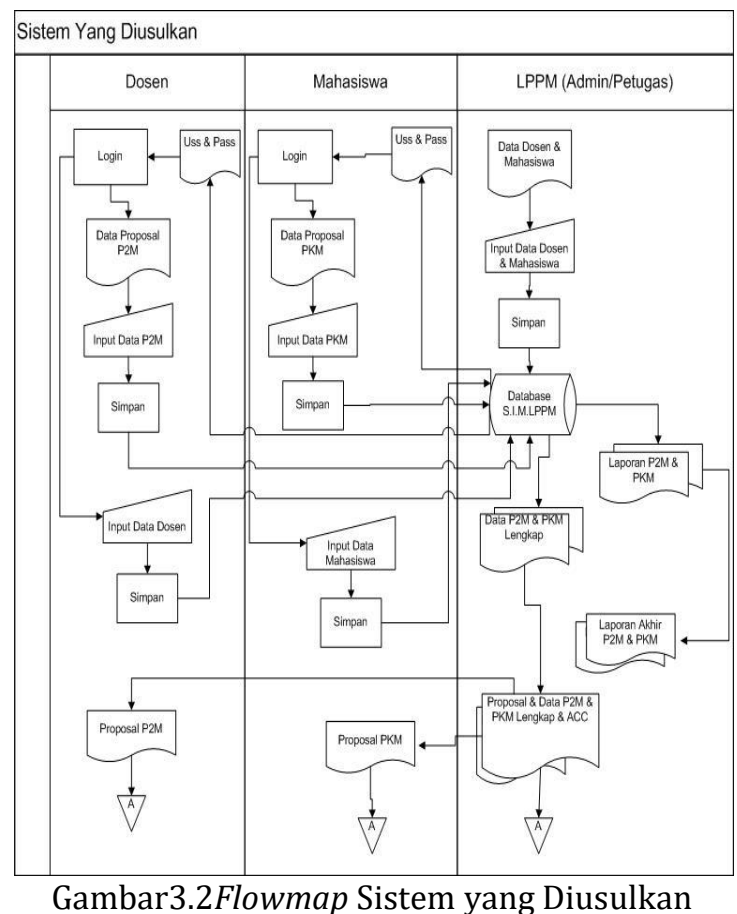

b. Iterface

1. Form Login

Form ini merupakan form pembuka sebelum masuk kedalam menu utama masing-masing, baik admin, dosen maupun mahasiswa terlebih dahulu harus mengisi form login yang berfungsi sebagai pengaman program. Saat mengisi form login akan diminta username dan password terlebih dahulu. Bila terjadi kesalahan dalam pengisisan username dan password maka akan ditampilkan suatu pesan kesalahan yaitu maaf username dan password yang anda masukan salah, bila benar maka akan dilanjutkan ketampilan menu masing-masing. Pada form username dan password ini data yang dimasukan harus benar dengan data yang tersimpan dalam database. 

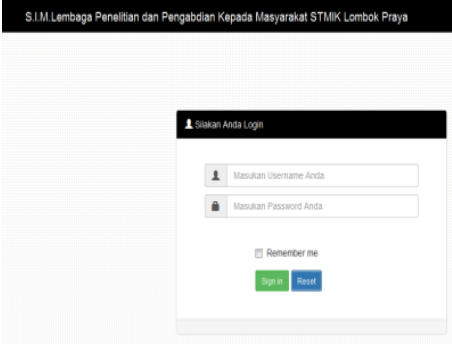

Gambar 4.1 Form Login

2. Form Input Data Dosen

Form ini di isi oleh dosen tentang identitas data dosen itu sendiri. Form input data dosen berfungsi untuk penginputan data dosen yang tersedia dalam sistem ini.

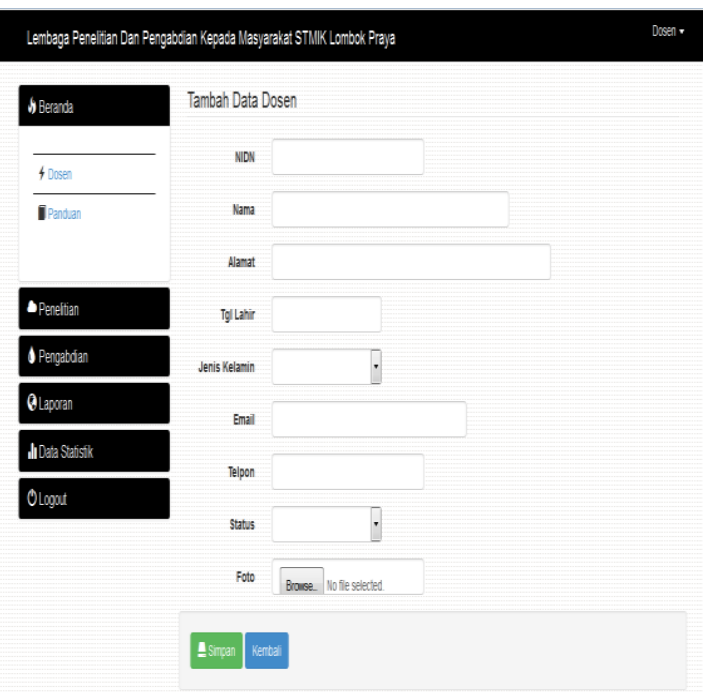

Gambar 4.2 Form Input Data Dosen

3. Form Input Data Pengabdian

Form ini di isi langsung oleh dosen. Form input data pengabdianberfungsi untuk dosen mendaftarkan diri dan menginputkan data yang sesuai dengan data pengabdian yang sudah ada dalam melaksanakan sebuah pengabdian kemudian akan tersimpan dalam sistem ini.

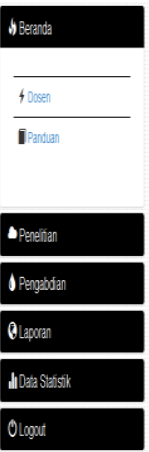

Tambah Data pengabdian

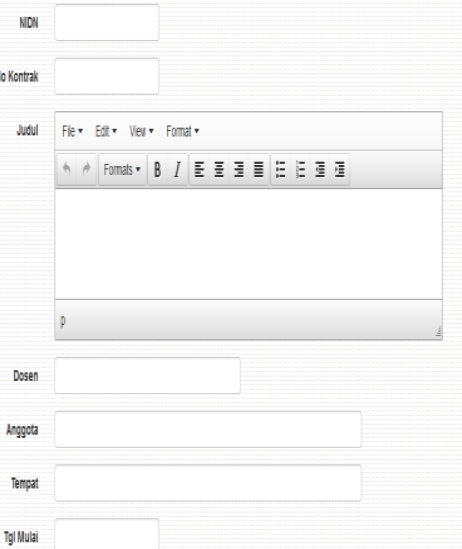

Gambar 4.3 Form Input Data Pengabdian

\section{Form Input Data Penelitian}

Form ini di isi langsung oleh dosen. Form input data penelitianberfungsi untuk dosen mendaftarkan diri dan menginputkan data yang sesuai dengan data penelitian yang sudah ada dalam melaksanakan sebuah penelitian dan kemudian akan tersimpan dalam sistem ini.

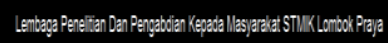

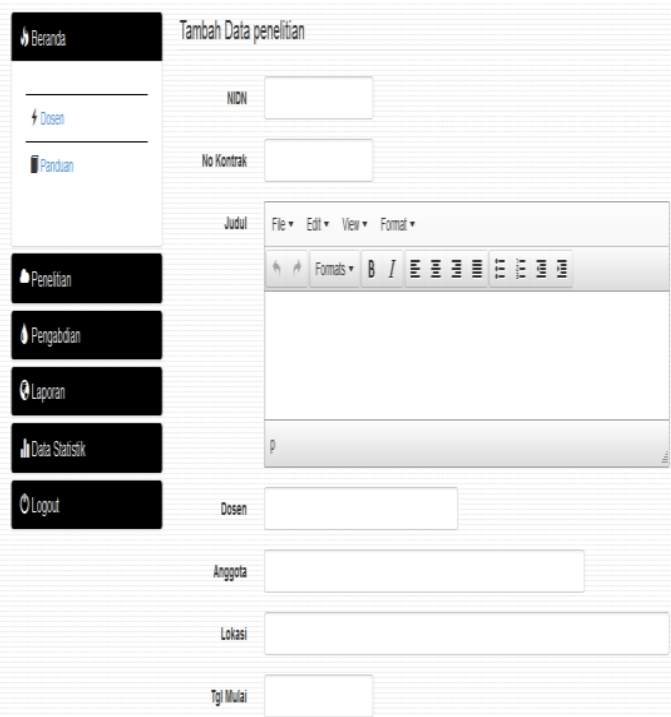

Gambar 4.4 Form Input Data Penelitian

5. Form Input Data Mahasiswa

Form ini di isi oleh mahasiswa tentang identitas data diri. Form input data mahasiswa berfungsi untuk penginputan data diri yang tersedia dalam sistem ini. 


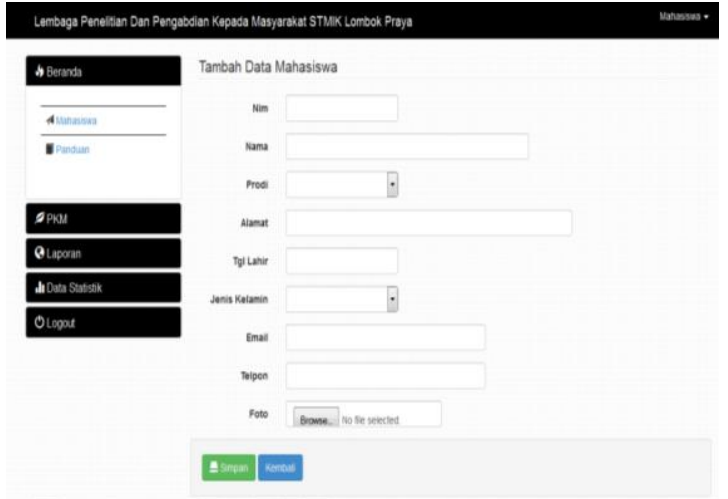

Gambar 4.5 Form Input Data Mahasiswa

6. Form Input Data PKM (Program Kreativitas Mahasiswa).

Form ini di isi langsung oleh mahasiswa. Form input data program kreativitas mahasiswaberfungsi menginputkan data untuk program kreativitas mahasiswa dan kemudianakan tersimpan dalam sistem ini.

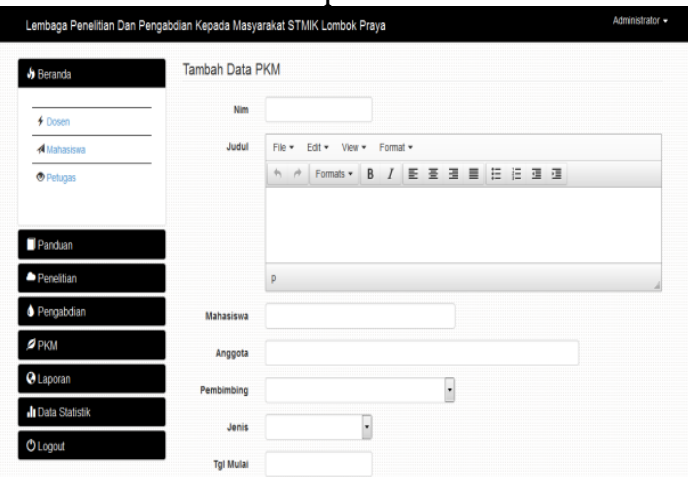

Gambar 4.6 Form Input Data Program Krativitas Mahasiswa

7. Tampilan Form Data Dosen

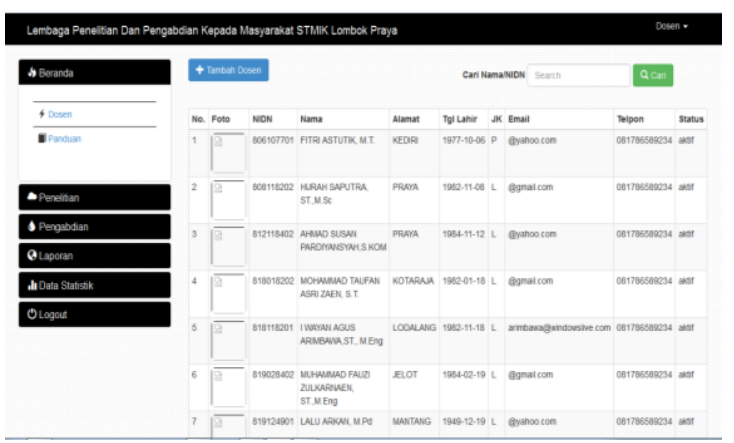

Gambar 4.7 Tampilan Form Data Dosen

8. Tampilan Form Data Penelitian

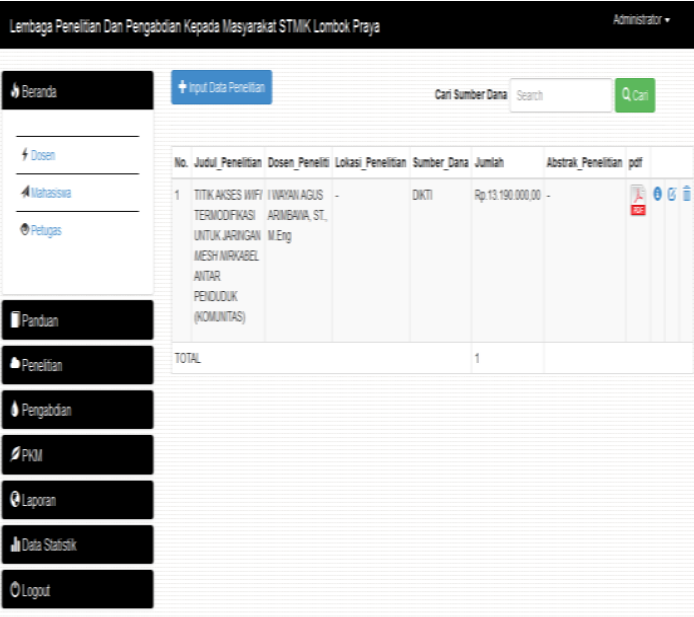

Gambar 4.8 Tampilan Form Data Penelitian

9. Tampilan Form Data Program Kreativitas Mahasiswa

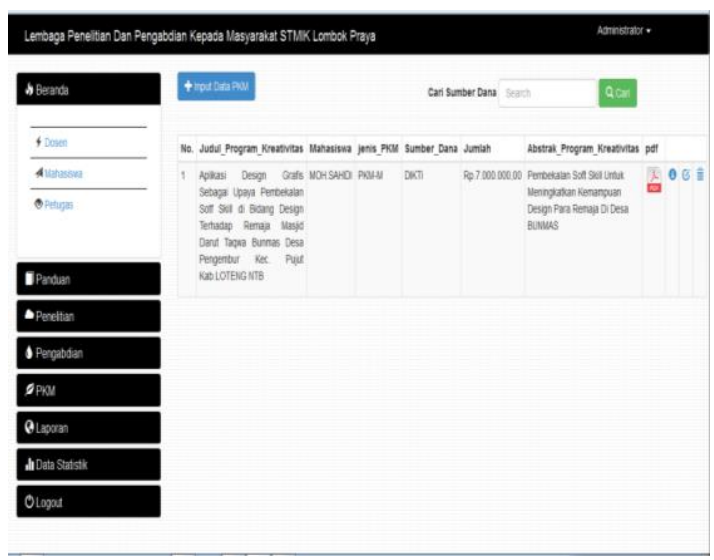

Gambar 4.9 Tampilan Form Data Program Kreativitas Mahasiswa

10. Tampilan Form Laporan Penelitian

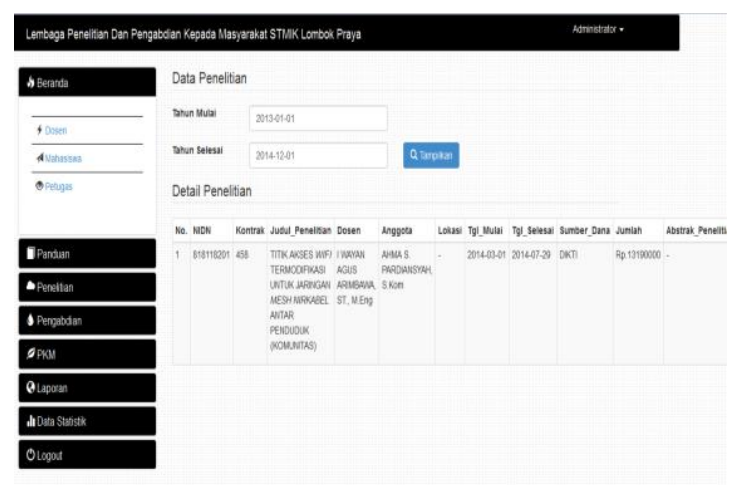

Gambar 4.10 Tampilan Form Laporan Data Penelitian 


\section{Tampilan Form Data Statistik}

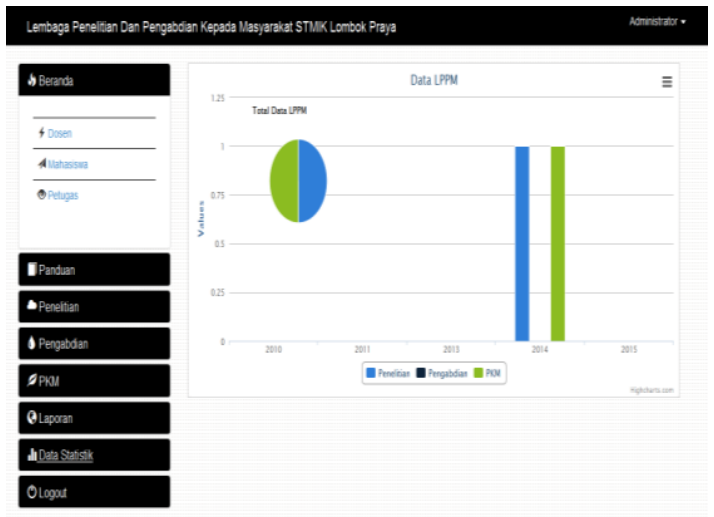

Gambar 4.11 Tampilan Form Data Statistik

Pada form data statistik ini berfungsi untuk menampilkan data statistik menggunakan grafik, yang diambil dari data tahunan yang sudah masuk baik itu berupa data PKM (Program Kreativitas Mahasiswa), data penelitian maupun data pengabdian.

\section{Kesimpulan dan Saran}

A. Kesimpulan

Dari hasil uraian di atas mengenai Sistem Manajemen Lembaga Penelitian dan Pengabdian Kepada Masyarakat STMIK Lombok Praya dapat disimpulkan bahwa:

1. Penyajian informasi pada lembaga penelitian dan pengabdian pada masyarakat STMIK lombok praya yang meliputi input data dosen, input data mahasiswa, input data PKM (Program Kreativitas Mahasiswa), input data pengabdian, input data penelitian, data dosen, data mahasiswa, data PKM, data penelitian dan data pengabdian. Disajikan dalam bentuk basis data yang di update oleh petugas maupun administrator mulai dari input data dosen maupun mahasiswa, PKM, pengabdian dan penelitian secara keseluruhan, sehingga dosen atau mahasiswa dapat mengakses, melihat dan menginput data untuk mendaftar pada sistem ini.

2. Penyajian informasi pada lembaga penelitian dan pengabdian pada masyarakat STMIK Lombok Praya menghasilkan beberapa output yaitu berupa form laporan data dosen, data mahasiswa, data PKM, data pengabdian, data penelitian dan data statistik.

B. Saran

Kesimpulan dari sistem yang sedang dibuat adalah sebagai berikut:
1. Perlunya dilakukan pengembangan sebuah sistem yang lebih lengkap agar mampu menangani semua kegiatan yang dilakukan pada penelitian dan pengabdian pada masyarakat STMIK Lombok Praya.

2. Dengan sistem pengolahan data yang baru, pemakai disarankan untuk memperhatikan kekurangan dan kelemahan sistem agar dapat segera dicari pemecahan masalahnya dan dapat segera diperbaiki kembali.

3. Bagi peneliti lain yang ingin mengambil penelitian dengan judul yang sama diharapkan mampu memperbaiki kesalahankesalahan maupun kekurangan-kekurangan yang ada pada sistem informasi yang telah dibuat supaya sistem dapat digunakan sebaik-baiknya.

\section{DAFTAR PUSTAKA}

[1] Kurniawan, Ahmad., dkk., (2015). "Penerapan Dashboard Business Intellegence Pada Penelitian Pelayanan/Pengabdian Kepada Masyarakat dan Kerjasama”. Agustus 2015.

[2] Dyan Risma Wardani, dkk., (2015). "Sistem InformasiManajemen Penelitian dan pengabdian Kepada Masyarakat Polines". Vol .001.

[3] Fadli, S., Sunardi, S., (2018). Perancangan Sistem Dengan Metode Waterfall Pada Apotek XYZ. Jurnal Manajemen Informatika dan Sistem Informasi (hal. 29-35). Praya: STMIK Lombok.

[4] Fadli, Sofiansyah. "Model Rapid Application Development Dalam Pengembangan Sistem Reservasi Dan Penyewaan Kamar Hotel." JIRE: Jurnal Informatika \& Rekayasa Elektronika. 1.1 (2018): 57-64.

[5] Jery Ariska, M.Jazman., (2016), "Rancang Bangun Sistem Informasi Manajemen Asset Sekolah Menggunakan Ternik Labelling QR Code," vol.2, No 2, Agustus.

[6] Munandar, Haris., Nurmiati, Siti., (2016). "Sistem Informasi Kegiatan Akademik Untuk Akreditasi Program Studi Berbasia WEB". Vol.5, No 5, Maret .

[7] Nurmi, Ellbert Hutabri., (2015). Membangun sistem pendukung keputusan penelitiandosen berbasis Online pada Unit Penelitian, Pengembangan dan Pengabdian Kepdan Masyarakat STKIP PGRI Sumatera Barat.Vol. 1 Oktober 2015.

[8] Saputra, Agus. (2011). "Trik Kolaborasi CodeInginter dan Jquery". Yogyakarta. Lokomedia. 
[9] Saputra, Agus., (2012). "Web Tips PHP, HTML5 dan CSS3". Jasakom, Jakarta.

[10] Subari Tata,. (2005). "Sistem Informasi Manajemen". Yogyakarta, CV Andi Offset.

[11] Sunardi., Fadli, Sofiansyah., (2018). "Identifikasi Masalah Penerapan Metode Agile (Scrum) Pada Pengembangan Perangkat Lunak Di Perguruan Tinggi." MISI (Jurnal Manajemen Informatika dan Sistem Informasi) 2.1.

[12] Sunardi., Fadli, Sofiansyah., (2018). "Sistem Informasi Pengolahan Data Kelapa Sawit Berbasis Client-Server." MISI (Jurnal Manajemen Informatika dan Sistem Informasi) 1.2.
[13] Yunitarini, Rika., (2014). "Sistem Informasi Manajemen Tata Kelola Aset Informasi Perhotelan (Studi Kasus: Hotel Mahkota lamongan". Jurnal Buana Informatika.

[14] Zulfiandri., Wardhani, Dyah Citra. (2015). "Rancang Bangun Sistem InformasiManajemen Aset Berbasis Private Cloud (Studi Kasus: TVRI Nasional)". Jurnal Simantec. Vol. 5, No. 1. 